\section{ESF scheme criticized}

\section{London}

AN initiative by the European Science Foundation (ESF) to integrate European research on schizophrenia could lead to an identification of the genetic loci associated with the disease within five years.

But reservations about the methodology and management of the scheme emerged at a discussion meeting on the molecular genetics of schizophrenia held here on 4 November. The meeting was sponsored by SANE (Schizophrenia: A National Emergency), a British charity founded in 1986.

In that same year, ESF launched a 'network' to establish a European database on pedigrees, to foster international collaboration, to create cell lines from patients and their families and above all to work out common criteria for the diagnosis of schizophrenia. At present the diagnostic criteria vary significantly from one country to another.

ESF overtures to raise the necessary FF88 million ( $\$ 14$ million) came to nothing, however, apparently because the national funding agencies from whom the money was sought were not satisfied that they would have enough say in exactly how the money would be spent. The ESF has now started a FF10 million pilot programme using money that it has raised itself, which has helped to win round other funding agencies.

The ESF programme was outlined at the London meeting by Jacques Mallet, of the CNRS (Centre Nationale de la Recherche Scientifique), but two general criticisms arose. First, funding bodies are likely to be unwilling to release funds to the scheme only for the ESF to pass it on to research groups it already supports. Dr Dai Rees, Secretary of the British Medical Research Council (MRC), said he had to be sure that the MRC "isn't being charged twice".

Second, the extent to which the ESF would wish to dictate terms to laboratories participating in the scheme is unclear. Researchers are concerned that participation might compromise their independence. They worry, for example, that the search for polymorphic markers on chromosome 7 could be allotted to researchers with expertise in chromosome 11 , and because they do not know to what extent ESF might license one group to perform linkage analyses between markers on data collected by others. Although Mallet gave the impression that the ESF would take full account of the preferences of individual groups, researchers and paymasters were left wanting to know a lot more before committing themselves fully.

Henry Gee

\section{Washington}

Two weeks ago, the National Science Foundation (NSF) decided not to continue to support the John von Neumann National Supercomputing Center in Princeton, New Jersey, beyond September 1990. The centre's director, Doyle Knight, now has a year to find other sources of money. The von Neumann centre's struggle for survival will be watched with concern by the other four NSF national supercomputing centres: with supercomputing capacity in the United States now eighty times greater than in 1985, when the NSF centres were begun, the provision of computing time and programming advice is no longer their sole province, and all of them are looking to justify their existence in other ways.

NSF's decision to cut off the Princeton centre caused no great surprise. It operated ETA-10 machines, whose manufacturer, Control Data Systems, got out of the supercomputer business earlier this year (see Nature 339, 246; 1989). The centre had proposed replacing the ETA10 s with a Cray system, but with three of the NSF centres already running Crays, the Princeton proposal was not considered sufficiently distinctive to merit support.

Knight responds that the distinctiveness of a supercomputer centre should be measured by more than "the label on the box", and points to Princeton's work in designing a comprehensible "English" interface between the supercomputer's operating language and the user as an example of the kind of pioneering development his centre was doing.

Nevertheless, Knight has no plans to fight the NSF decision, and is concentrating his energies instead on finding other means of support. These will include money from the state of New Jersey and from industrial clients as well as from academic users, but he emphasized that the von Neumann centre has no desire to become a consultancy or a time-sharing service: the technical staff now at Princeton are unlikely to stay if they have no time to work on their own research.

Although the Princeton centre has been forced into fighting for its existence, the other NSF centres are also facing challenges. Initiated at a time when supercomputer time in the United States was scarce and inaccessible, the NSF centres were meant not just to provide access but to be, as Thomas Weber, director of advanced scientific computing at the NSF, puts it, "evangelists". In that they have been successful. Nearly a dozen states have now set up their own supercomputer centres, and a number of companies that started by buying into the NSF centres have now bought their own machines.

But both Weber and Lisa Heinz, an analyst at the Congressional Office of Technology Assessment, argue that there is still plenty for the NSF centres to do. Weber points to the fact that at least one industrial client of the National Center for Supercomputing Applications in Champaign, Illinois, has remained a client even after buying its own machine, and Heinz says that national supercomputing centres, are needed to do jobs beyond the capabilities of individual institutions. Many scientists, she says, have been so keen to get their old programmes running on the new machines that they have done the least adaptation necessary; it is mainly the NSF centre staff who have looked for the most efficient ways to solve problems on supercomputers, and who have thereby acquired the foresight to look ahead to new applications.

This view of the future is shared by Charles Bender, director of the supercomputing centre at Ohio State University in Columbus, which is supported by the state of Ohio and provides supercomputer time on a Cray Y-MP free of charge to 22 universities in the state. His centre has a staff of about 40 people and an annual budget of $\$ 4.5$ million, which makes it smaller than the NSF centres only by a factor of three or four. But last week Bender chaired a meeting in Columbus of eight directors of regional centres who together controlled more supercomputing power than the five NSF centres. He therefore sees no reason why local centres should not be capable of doing all the things that NSF centres can do now.

The Ohio facility also has links with industry (an important reason for the state's support) and staff who do research in visualization and computing methods. Bender argues that the independence of his centre from the federal budget gives it more flexibility, for example in working on the programming capabilities offered by novel devices such as the 'transputer', a parallel-processing chip made by the UKbased company Inmos, now under the wing of French company Thomson CSF.

The time from installation of a new machine to its obsolescence seems to be four or five years, which also happens to be the age of the NSF centres. Four of the five are still thriving, and Weber argues that their undisputed success in raising up US supercomputing capability from almost nothing and moving their expertise into industry is a good argument to take before Congress in asking for continued support. But he has to hope that politicians, seeing independent supercomputing centres springing up and trying to do the same thing, will not decide in a few years time that the federal effort has succeeded, and that the baton should be passed to states and to industry. 